\title{
Arriesgar y preservar la vida: derechos humanos, conflicto sociopolítico armado y Trabajo Social en Colombia
}

\section{Cristian Sebastián Castaño-Orozco}

Trabajador Social. Especialista en Educación en Derechos Humanos

Universidad Icesi. Cali, Colombia

https://orcid.org/0000-0002-3011-1989 • cristian.castano1@correo.icesi.edu.co

\author{
Ricardo Patiño-Martínez \\ Trabajador Social \\ Alcaldía de Argelia. Cauca, Colombia \\ https:// orcid.org/0000-0002-1854-655X • ricardomartinezdj@gmail.com
}

\section{Resumen}

Este artículo se propone mostrar un panorama del movimiento por la defensa de los Derechos Humanos en Colombia, en relación con el desarrollo de una estrategia contrainsurgente, como una oportunidad para el ejercicio profesional del Trabajo Social. Para lograrlo, examina una serie de posibilidades de acción relacionadas con la formación y la acción profesional que permitan aportar a la construcción de una Paz con Justicia Social en Colombia.

Palabras clave: Derechos Humanos; Estrategia contrainsurgente; Conflicto sociopolítico armado; Trabajo Social.

Recibido: 15/03/2019| Aprobado: 18/10/2019

c) (i)(-) Esta obra está bajo una Licencia Creative Commons Atribución-NoComercial-CompartirIgual $\underline{4.0 \text { Internacional. }}$

¿Cómo citar este artículo? / How to quote this article?

Castaño-Orozco, C.S., y Patiño-Martínez, R. (2020). Arriesgar y preservarla vida: derechos humanos, conflicto sociopolítico armado y Trabajo Social en Colombia. Prospectiva. Revista de Trabajo Social e intervención social, (30), 283-307. doi: 10.25100/ prts.v0i30.7448. 
Castaño-Orozco y Patiño-Martínez

\title{
Risk and Preserve Life: Human Rights, Armed Sociopolitical Conflict and Social Work in Colombia
}

\begin{abstract}
This article seeks to create an overview of the movement for the defense of Human Rights in Colombia, in relation to the development of a counterinsurgency strategy as an opportunity for the professional exercise of Social Work position. We examine a series of possibilities of actions within the training and professional performance of a social worker to contribute to the construction of peace and social justice in Colombia.

Keywords: Human Rights; Counterinsurgency strategy; Armed sociopolitical conflict; Social Work.

Sumario: 1. Introducción; 2. Panorama general de la estrategia contrainsurgente en Colombia; 3. Derechos Humanos y Trabajo Social en Colombia: inserción a un movimiento; 4. Posibilidades de acción desde el Trabajo Social en Derechos Humanos: Sobre tiempos de incertidumbre y esperanza; 5. Referencias bibliográficas.
\end{abstract}




\section{Introducción}

Dedicado a Cristina Bautista e Iván Velasco López, personas que hicieron del Trabajo Social una acción viva en conjunto con las comunidades, protegiéndolas y haciéndoles valer sus derechos. Sus vidas sacrificadas no caerán en vano en la lucha por la Paz, la Democracia y la Justicia Social en Colombia.

En los últimos años se ha puesto en boga en medios de comunicación y círculos académicos la preocupación por el asedio que sufren las y los defensores de Derechos Humanos en Colombia. La literatura sobre el conflicto armado en Colombia es sumamente extensa, contando con un sinnúmero de estudios de caso, análisis y balances acerca de sus orígenes, surgimiento y dinámicas a partir de cada uno de los actores involucrados, así como los impactos que dejan en la sociedad civil y las acciones de esta última para resistir los embates de la guerra. De igual forma, la perspectiva desde las cual se hace el análisis de esta temática tan importante para la investigación es sumamente diversa; basta tan solo con revisar los ensayos y las relatorías de la Comisión Histórica para las Causas del Conflicto y sus Víctimas, instancia creada entre los años 2014 y 2015, en el marco de los Diálogos entre el gobierno de Juan Manuel Santos y la Delegación de Paz de las Fuerzas Armadas Revolucionarias de Colombia - Ejército del Pueblo FARC-EP, para dar cuenta de tal diversidad en las posiciones de sus autores ${ }^{1}$. De estos ensayos, tan solo los denominados "críticos" -porque sus autores fueron escogidos por la Delegación de Paz de las FARC-EP- hacen una importante referencia a la situación de los Derechos Humanos en Colombia, en especial el ensayo de Javier Giraldo (2015). De resto, se ha generado una suerte de "historia oficial" en donde categorías como contrainsurgencia, "enemigo interno" y movimiento por la defensa de los Derechos Humanos aparecen de forma residual o como categorías sujetas a la crítica por contener una "carga ideológica" que nubla el análisis “objetivo" del fenómeno en revisión.

Contrario a lo que se cree, el conflicto sociopolítico armado en Colombia cuenta con infinidad de páginas pendientes por escribir. Muchas de estas páginas tienen que ver con el hecho de entender dicho conflicto como una estrategia contrainsurgente, de la cual es posible reconocer el trabajo realizado por autores como Germán Palacio (1990), Vilma Franco (2009), Jairo Estrada (2015), Javier Giraldo (2015), Hernando Calvo-Ospina (2008) y Forrest Hylton (2006), entre otros. Sin embargo, el presente artículo pretende establecer la importancia de las afectaciones de dicha estrategia sobre el movimiento por la defensa de

1 Como relatores de la Comisión están Eduardo Pizarro León-Gómez, escogido por el Gobierno Santos, y Victor Manuel Moncayo, escogido por la Delegación de Paz de las FARC-EP. Las autorías de los ensayos señalados corresponden a dos grupos de personas escogidas. Por parte del gobierno Santos: Jorge Giraldo, Gustavo Duncan, Maria Emma Wills, Vicente Torrijos, Daniel Pecaut, Francisco Gutiérrez Sanin. Por su parte, los autores escogidos por la Delegación de Paz de las FARC-EP fueron Jairo Estrada, Sergio de Zubiría-Samper, Renán Vega Cantor, Alfredo Molano, Darío Fajardo y Javier Giraldo S.J. 
los Derechos Humanos, sobre todo por el papel que dichas organizaciones han jugado en medio del conflicto como garantes de las protestas sociales y preservadoras de vidas que permanentemente corren riesgo por expresar una voz crítica frente al orden social existente, razón por la cual su ejercicio se entrecruza con los conflictos sociales no resueltos aún en nuestro país.

Sobre este movimiento se cuenta con pocos trabajos de orden académico, rescatando tal vez los aportes de Winifred Tate (2007), Flor Alba Romero (2001; 2010) e Iván OrozcoAbad (2005). Sin embargo, este vacío es colmado con las voces de las propias organizaciones de Derechos Humanos, quienes en sus informes e iniciativas propias de memoria logran contar, de primera mano, su situación y riesgo latente en relación con el conflicto sociopolítico armado y las dinámicas contrainsurgentes que sobre ellas acaecen, destacando entre ellos el trabajo del Centro de Investigación y Educación Popular-CINEP (2004; 2011) la Comisión Colombiana de Juristas-CCJ (2013), el Movimiento Nacional de Víctimas de Crímenes de Estado-MOVICE (2013), el Colectivo de Abogados José Alvear Restrepo (Arenas y Girón, 2014) y organizaciones de orden internacional como Pax Christi \& Justitia EtPax Netherlands (1988) y Terre-Des Hommes (1995).

De ahí que este escrito apuesta por recuperar algunos momentos históricos en el movimiento por los Derechos Humanos en Colombia en relación con un panorama hostil a su ejercicio, visibilizando de igual forma su crecimiento y profesionalización, de tal modo que ha permitido el ingreso de profesionales en Trabajo Social y otras Ciencias Sociales a fortalecer su ejercicio y fin misional de garantizar el bienestar de las comunidades y sus derechos. La tesis principal de este escrito precisa que la situación actual de los Derechos Humanos en Colombia, inserto en un conflicto sociopolítico armado, se constituye como motivante para la participación de profesionales en Trabajo Social dentro del movimiento por la defensa de los Derechos Humanos, lo que promueve, a su vez, la construcción de otras posibilidades de participación y ejercicio profesional acorde con un proyecto éticopolítico profesional crítico y en permanente construcción con las fuerzas vivas de la sociedad en los territorios.

Para desarrollar esta tesis partimos de tres elementos fundamentales: un primer elemento describe el panorama general de la estrategia contrainsurgente en Colombia en contra de las expresiones armadas y no armadas de crítica al orden social existente. Un segundo elemento ubica el movimiento por la defensa de los Derechos Humanos en un contexto y periodicidad de tiempo que les ha permitido establecer algunos avances y conquistas en torno a su ejercicio como garantes de los derechos de las comunidades, definiendo así oportunidades para el ejercicio profesional de Trabajo Social. Por último, se analizan los desafíos en cada uno de los ámbitos donde el Trabajo Social puede incidir en la defensa de los Derechos Humanos en Colombia como son: la formación profesional, la investigación social, la praxis profesional y la organización gremial. 
Castaño-Orozco y Patiño-Martínez

Este artículo se inspira en el trabajo de investigación Constitución de la Red Popular para la Defensa de los Derechos Humanos en el Valle del Cauca 2014-2015 (Castaño y Patiño, 2016), desarrollado por los autores, en especial del Capítulo 4, que corresponde al contexto de sistematización. Sin embargo, los avances y enriquecimientos que cada uno ha desarrollado en su ejercicio académico y profesional permiten que dicho capítulo sea tomado como una base de trabajo haciendo algunas precisiones con nuevos elementos que profundizan y enriquecen el análisis.

Este texto se aborda desde una perspectiva crítico-marxista, que permite el análisis y comprensión de la realidad para develar los fundamentos socio-históricos y las contradicciones existentes en el contexto, que traen como consecuencias inmediatas la existencia de una lógica dominante y de unos procesos de resistencia que emergen con el propósito de levantar nuevas lecturas del contexto y proponer alternativas frente a tal lógica.

De igual forma, como técnica para la realización del estudio se parte del análisis documental de textos académicos e informes desarrollados por diversas organizaciones de Derechos Humanos, cuya información se entremezcla con la propia experiencia de los autores como defensores de Derechos Humanos pertenecientes a diferentes organizaciones como el Comité para la Defensa de los Derechos Humanos y el Movimiento Político y Social Marcha Patriótica, quienes en sus acompañamientos a algunos conflictos sociales acontecidos en el Valle del Cauca y en el departamento del Cauca, permiten hacer una retroalimentación que se traduce en posibilidades de acción a partir del ejercicio profesional del Trabajo Social en relación con la defensa de los Derechos Humanos en Colombia.

\section{Panorama general de la estrategia contrainsurgente en Colombia}

"Pese a la politica de olvido que caracteriza la manera como en Colombia se enfrenta el pasado de guerras y pobreza, ese tiempo nos llega de las más diversas formas para constituirnos"

Vilma Franco - Orden contrainsurgente y dominación

Hernando Calvo-Ospina (2008) ha de ubicar como punto de partida para lo que él denomina "terrorismo de Estado" en Colombia, la traición cometida por Francisco de Paula Santander contra Simón Bolívar en Septiembre de 1828, cuando ordena atentar contra su vida. Este texto no pretende ubicar tal panorama demasiado lejos, pero sí quiere precisar que, desde los inicios de la vida republicana, la codicia y el afán de poder de sectores de la sociedad pertenecientes a un bloque de poder dominante, ha desatado toda serie de prácticas sistemáticas de violación a los Derechos Humanos contra otros sectores de la sociedad que cuestionan un orden social capitalista y ejercen, frente a ello, diversas acciones para la transformación de dicho orden. Tales prácticas son realizadas 
principalmente por diversos actores que cuentan con la capacidad para proteger y perpetuar el actual orden social capitalista mediante mecanismos violentos, con el argumento de contrarrestar a sectores armados de la sociedad encargados de alterar dicho orden.

A pesar de que la Constitución Política de Colombia (1991), en su Artículo 2, trata del deber del Estado de garantizar los derechos de su población, lo cierto es que este mismo se ha convertido en uno de sus principales transgresores, por acción o por omisión. Una de las manifestaciones de esta escalada de acciones-omisiones violatorias de los Derechos Humanos de la población tiene que ver con la estrategia contrainsurgente que se adelanta en el marco de la lucha de clases, en una escalada que tiene como fin primordial erradicar la supuesta "amenaza comunista" (CINEP, 2004; Franco, 2009; Giraldo, 2015; MOVICE, 2013) que se expande en el país a través de las movilizaciones sociales y de las organizaciones armadas insurgentes. Dicha estrategia se expresa en acciones diversas desarrolladas por actores diversos -gobierno, fuerza pública, configuraciones paramilitares, medios de comunicación- en un permanente tránsito entre la legalidad y la ilegalidad, buscando con ello la legitimación de un orden social y la superación de otros de carácter alternativo al existente.

Para el caso colombiano, existen dos elementos transversales que han de configurar el desarrollo de la estrategia contrainsurgente en Colombia: un primer elemento tiene que ver con la figura del Estado de Sitio, presente en la Constitución Política de Colombia (1886), cuyo Artículo 121 le entregaba al presidente de la República la facultad de decretar el Estado de Sitio en caso de "guerra externa" o "conmoción interna". Sumado a esta figura, el Artículo 170 de aquella Constitución plantea que los delitos cometidos por militares en el servicio activo, y en relación con el servicio activo, serían prescritas por el Código Penal Militar (Calvo-Ospina, 2008). Ambos artículos dieron pie para el abuso de autoridad por parte de la fuerza pública, una de las principales transgresoras de los Derechos Humanos, mientras que la figura del Estado de Sitio fue empleada, aproximadamente, en un 75\% del tiempo comprendido entre 1958 y 1991.

El otro elemento transversal que configura la estrategia contrainsurgente tiene que ver con la configuración de la Doctrina Militar, sujeta a la relación de "subordinación estratégica" por parte de las Fuerzas Militares colombianas sobre las estadounidenses (Vega-Cantor, 2015). Dicha doctrina fue adoptada como oficial por parte del estado colombiano mediante varias normas, entre ellas el Decreto 3398 de 1965, convertido en legislación permanente mediante la Ley 48 de 1968 o Estatuto Orgánico de Defensa Nacional (MOVICE, 2013). Como punto especial, será este Decreto/Ley, en su Artículo 33, el que permite al Ejército la conformación de "grupos" o "juntas" de autodefensa, cuerpos civiles armados que, más adelante, habrán de conformarse como ejércitos privados y grupos paramilitares que habrán de acechar al país hasta la actualidad. De igual forma, 
dicha doctrina se establece a partir de Manuales de Instrucción en los programas de estudios de curso por parte de la Escuela Superior de Guerra, los cuales han de establecer puntos importantes para la estrategia contrainsurgente como son: conceptos de "enemigo interno" y "subversión"; actividades a desarrollar en el marco de la disputa y victoria del "enemigo interno"; herramientas jurídicas para el desarrollo de actividades de inteligencia y contrainteligencia y juzgamiento a personas capturadas en el marco de su ejercicio y formas organizativas entre las ramas de la fuerza pública en colaboración con la población civil.

Estos elementos transversales habrán de ser fuertemente explotados durante la década de 1970, la cual marca un derrotero importante para las luchas sociales y la estrategia contrainsurgente en Colombia. Frente a las contundentes acciones de movilización protagonizadas por las y los estudiantes en 1971, el campesinado en 1972 y las centrales obreras de 1977, la respuesta del Estado se concentró en contener dichas protestas mediante mecanismos jurídicos de represión contra las comunidades enardecidas por los incumplimientos del Estado. Muestra de ello fue la expedición, por parte de Julio César Turbay Ayala (1978-1982) del Decreto 1923 de 1978, denominado también Estatuto de Seguridad, el cual permitió al ejecutivo endurecer las penas para el delito de rebelión - que pasó de cinco a nueve años para quienes tomaran parte en el alzamiento, y de ocho a doce años para quienes lo lideraran- y la atribución al juzgamiento de éste y otros delitos políticos por parte de la justicia penal militar mediante el procedimiento de Consejos de Guerra Verbales (Grupo de Memoria Histórica, 2013, p. 208).

No contento con las acciones legales de represión, el Estado colombiano, mediante la fuerza pública, se ha encargado de conformar estructuras clandestinas y operaciones encubiertas, con el propósito de hostigar el ejercicio de dirigentes políticos y de las nacientes organizaciones de Derechos Humanos que, frente a la escalada represiva de los gobiernos de turno, se empezaron a conformar. Tanto MOVICE (2013) como la CCJ (2013) hacen recuento de casos como el Batallón de Inteligencia y Contrainteligencia BINCI "Brigadier General Charry Solano" y la conformación del grupo Alianza Anticomunista Americana -Triple A- a finales de la década de 1970, el Batallón Ayacucho y la conformación del grupo "Muerte A Comunistas MAC" en 1986, el Grupo Hure del Magdalena Medio y la conformación del grupo Muerte a Revolucionarios y Comunistas en 1989 y la Red Número 7 de Inteligencia de la Armada Nacional entre 1992 y 1993, todos ellos involucrados en acciones de atentados contra sedes sindicales y de prensa así como el asesinato y la ejecución extrajudicial de integrantes pertenecientes a organizaciones sociales y populares en los territorios.

Estas acciones encubiertas serán características de la década de 1980, cuando el Estatuto de Seguridad del -entonces- presidente Turbay es derogado por las acciones de 
las organizaciones de Derechos Humanos. Sin embargo, con el desmonte de las acciones legales de represión entran a jugar un papel importante las acciones ilegales, dando un giro a la "guerra sucia". Serán referentes para la época el grupo Muerte a Secuestradores MAS y otras iniciativas de corte paramilitar que surgen en poblados como Amalfi (Antioquia) y Puerto Boyacá (Boyacá) (Ronderos, 2014). Así mismo, la "guerra sucia" coincide con los movimientos de capital proveniente del narcotráfico dentro de la economía nacional, contribuyendo al proceso de transición de una industrialización dirigida por el Estado hacia un régimen de acumulación flexible ${ }^{2}$ (Estrada, 2008). Esta articulación promueve una etapa de estabilidad macroeconómica en la economía colombiana, una característica excepcional frente a la profunda crisis que atravesaban los países latinoamericanos en cuanto al aumento de la deuda externa y de las tasas de inflación, que obligó a estos países a establecer ajustes severos en sus economías para poder mantener accesibilidad a créditos externos e ingresar al ámbito internacional (Jiménez, 2008). Consecuencia de dicha articulación, será la alianza económica entre el capital producto de actividades ilícitas, -que, entre otras, contribuyeron al financiamiento del paramilitarismo y la "guerra sucia" - y la prosperidad de los grandes negocios capitalistas privados en los sectores de comercio y de servicios.

Con el arribo de dichas estructuras en la dinámica del conflicto sociopolítico armado, el ejercicio hegemónico de represión hacia los sectores populares y de oposición al orden social existente pasa de las prácticas de tortura, las detenciones ilegales y el juzgamiento de civiles por tribunales militares, a la práctica de asesinatos, masacres y desapariciones forzadas (Andreu, 2001). Sin embargo, será en la década de 1980 cuando los gobiernos de turno empiezan a demostrar acciones de respeto hacia los Derechos Humanos y la construcción de paz, aspectos que fueron limitados en los gobiernos anteriores. Entre dichas acciones se encuentran el inicio de conversaciones entre el gobierno de Belisario Betancur (1982-1986) y las FARC-EP, el nacimiento de instancias como la Consejería Presidencial para los Derechos Humanos en el año 1987 y la Procuraduría Delegada para los Derechos Humanos en 1990, la Consultoría para los Derechos Humanos y el Desplazamiento -CODHES- en 1992, así como la Unidad de Derechos Humanos de la Fiscalía, creada en 1994.

No obstante, el hecho más importante por destacar fue la realización de la Asamblea Nacional Constituyente que determinó la adopción de la Constitución Política de 1991. Frente a este último hecho, cabe destacar que la carta de derechos consignada en ella es amplia, dado el nivel de amplitud en la participación de sectores como la población

2 Por régimen de acumulación flexible se entiende el conjunto de procesos como "racionalización, reestructuración e intensificación del control sobre la fuerza de trabajo... El cambio tecnológico, la automatización, la búsqueda de nuevas líneas de producto y de nichos de mercado, la dispersión geográfica hacia zonas con controles laborales más cómodos, fusiones y medidas destinadas a acelerar el giro del capital" (Harvey, 1998, p. 170), que constituyen las bases de la economía neoliberal. 
indígena y la afro descendiente, así como también la de representantes de grupos armados recién desmovilizados como el M-19 y el Ejército Popular de Liberación EPL. Solamente será hasta la promulgación de la Constitución de 1991 cuando el Estado colombiano, constituido ahora como Estado Social de Derecho, reconoce la existencia jurídica de los Derechos Humanos en toda su extensión. Se reconocen, entonces, los “derechos humanos de primera, segunda y tercera generación; es decir, derechos civiles y políticos, algunos derechos económicos, sociales y culturales como el empleo, la vivienda, la salud, la cultura y derechos de tercera generación, como el derecho a la paz, el cual no sólo es un derecho ciudadano sino un objetivo básico del orden constitucional" (Romero, 2010, p. 158). De igual forma, la autora reconoce que en esta constitución se amplía el campo de protección de los derechos desde el propio Estado, con la creación de la Defensoría del Pueblo y la ampliación de la normatividad de protección como la acción de tutela3instalando de esta forma un camino que en adelante será utilizado por los ciudadanos y ciudadanas colombianos, en la exigibilidad de sus derechos.

Sin embargo, estos adelantos se ven empañados por acciones jurídicas que pretenden generar continuidad práctica a la figura del Estado de Sitio, modificada a propósito en la Constitución de 1991, mas no proscrita. Entre 1988 y 1990, el presidente Virgilio Barco (1986-1990) expide dos estatutos que, bajo el argumento de preservar el "orden público" y como respuesta al "terrorismo", vuelve y arremete contra las organizaciones populares por medio de la "guerra legal". Será bajo el Decreto 678 de 1988 y el Decreto 2790 de 1990 que se aplican los Estatutos para la defensa de la democracia y el Estatuto para la defensa de la justicia los cuales, en esencia, se encargan de establecer procedimientos jurídicos tales como: recortes a garantías judiciales ${ }^{4}$, definición ambigua del delito de terrorismo, tratamiento severo al delito político, y criminalización de las formas legales de protesta política (Andreu, 2001). De igual forma, durante el gobierno de César Gaviria (1990-1994) se expiden la Ley 15 de 1992 y la Ley 104 de 1993, que se encargan de poner en secreto todo el proceso jurídico -desde los jueces hasta los testigos-, se aprueba la detención preventiva de sujetos como única medida de aseguramiento, y se otorga un amplísimo poder de investigación a las fuerzas militares. Del otro lado, la llamada política de sometimiento del gobierno Gaviria continúa por el camino de la excepcionalidad jurídica para endurecer las penas. Es así como introduce:

innovaciones procesales que chocaban con los más elementales principios del garantismo penal, autoriza utilizar el Estatuto Antiterrorista (aprobado bajo el gobierno

3 La Acción de Tutela es un mecanismo de participación ciudadana, instaurado en el Artículo 86 de la Constitución Política de Colombia (1991), cuyo propósito consiste en proteger los derechos fundamentales proclamados en la Carta Magna cuando se considere que éstos resulten vulnerados o amenazados por la acción o la omisión de cualquier autoridad pública.

4 Esto mediante el surgimiento de figuras como "justicia regional", "justicia secreta" o "justicia sin rostro". 
de Virgilio Barco) para recortar las libertades públicas de otros sectores sociales distintos a los narcotraficantes y afectar significativamente el principio de igualdad ante la ley penal. (Grupo de Memoria Histórica, 2013, p. 223).

Así mismo, el paramilitarismo se expande de manera definitiva a nivel nacional mediante la expedición del Decreto 356 de 1994, el cual permite la conformación de servicios particulares de seguridad y vigilancia privada que operarían en zonas de combate donde el orden público fuese precario. Este decreto fue creado como una retribución a la efectiva colaboración del grupo de los Pepes ${ }^{5}$, cuyos jefes contaron entonces con amplias garantías para conformar, dirigir y operar estas cooperativas de seguridad como base de la expansión del paramilitarismo (Movimiento de ReconciliaciónFOR y Coordinación Colombia-Europa-Estados Unidos-CCEEU, 2014).Su creación y operación con armas de guerra en diversos departamentos del norte del país se fomentó desde la Gobernación de Antioquia en el período 1995-1997, bajo el mandato del entonces gobernador -y hoy expresidente y senador de la República- Álvaro Uribe Vélez (20022010).

A la creación y desarrollo de las organizaciones de "seguridad y vigilancia privada" a nivel nacional, se suma un hecho que fortalece de manera cuantitativa la alianza entre actores estatales, paramilitares, narcotraficantes y sector privado, y cualifica más la estrategia contrainsurgente: la conformación, en el año de 1997 de las Autodefensas Unidas de Colombia AUC. Esta organización se constituye como una federación que cobija a las diferentes estructuras paramilitares existentes a lo largo y ancho del país, unificando de esta manera la estrategia de liquidar de manera violenta toda expresión opositora al orden social existente, acrecentar la acumulación de capital legal e ilegal, favoreciendo de igual manera a intereses políticos y económicos particulares. Dicha unificación fue promovida y comandada por Carlos Castaño, comandante de las Autodefensas Campesinas de Córdoba y Urabá ACCU, y en ella ejerció el mando de una decena de miles de personas que se movilizan por los rincones de la geografía nacional, financiados por sectores de empresarios, terratenientes y narcotraficantes, en su objetivo por eliminar las guerrillas y su base poblacional.

En dicha dinámica expansiva, Castaño ordena la conformación de agrupaciones paramilitares a lo largo y ancho del país, sea por iniciativa propia o por petición de personas pertenecientes a las clases dominantes del departamento y apoyados por las nuevas élites del narcotráfico, antiguos militares y empresarios rurales, quienes expresaron sus preocupaciones por el accionar de las insurgencias de las FARC-EP y el

5 Acrónimo de "Perseguidos por Pablo Escobar", un grupo de narcotraficantes y paramilitares, anteriores aliados de Pablo Escobar, que comandados por los hermanos Fidel, Carlos y Vicente Castaño y Diego Fernando Murillo, alias Don Berna, actuaron en alianza con el Bloque de Búsqueda de la Policía Nacional en su guerra contra Pablo Escobar. 
ELN en sus terrenos. De acuerdo con un reciente informe del Centro Nacional de Memoria Histórica (2018), el modelo Castaño pretendió afianzar su dominio en el norte del país y atacar las retaguardias de las guerrillas en el sur, disputando el control hegemónico logrado por las FARC-EP, por ejemplo, en regiones como el Meta, Caquetá y Putumayo, esto mediante tácticas de terror dirigidas a la población civil y a las organizaciones sociales y de Derechos Humanos.

La llegada de Álvaro Uribe Vélez al gobierno implicó, no solamente la instauración de una medida de conmoción interior - una modalidad similar a la del Estado de Sitioentre Agosto del 2002 y Abril del 2003, sino que abre la puerta para una negociación de paz con las AUC. Dicha negociación, de acuerdo con MOVICE, no se trata sino de un modelo de "reciclaje" del fenómeno del paramilitarismo por dos motivos: por un lado, se presenciaron fenómenos ficticios de supuesta "desmovilización" de personas que, más adelante, y con los vacíos de poder configurados, se rearmaron mediante nuevas configuraciones paramilitares mal llamadas bandas criminales o Bacrim (Centro Nacional de Memoria Histórica, 2014). Por otra parte, el MOVICE (2013) y Forrest Hylton (2006) plantean que la supuesta "desmovilización" del paramilitarismo ocurre de la mano con la vinculación de la población civil a la dinámica de la guerra mediante figuras como redes de informantes, soldados campesinos y familias guardabosques.

Mientras Uribe Vélez le abría las puertas a la "desmovilización" paramilitar, éste se las cerraba a las insurgencias armadas por cuenta de sus acciones tendientes, no solo a negar la existencia de un conflicto armado, sino a reforzar una política de enfrentamiento directo hacia sus estructuras con el fin de ser eliminadas por la vía militar. Frente a las relaciones con las organizaciones de Derechos Humanos, Flor Alba Romero (2010) plantea que el discurso sobre éstas oscila entre la estigmatización, la vulnerabilidad y riesgo, la violación de sus derechos y las campañas para su protección. Dicha autora recopila algunas afirmaciones del propio presidente Uribe e integrantes de su gobierno como Fernando Londoño, quienes en su momento definieron estas organizaciones como: "terroristas vestidos de civil", "aparato subversivo no armado", "estafetas de la guerrilla", "idiotas útiles de la insurgencia” y "brazo político de la guerrilla". Frente a esta campaña generalizada de estigmatización por parte del gobierno Uribe $\mathrm{y}$, en general, por las Fuerzas Militares, en el marco de la Doctrina Militar, juegan un papel importante los medios de comunicación oficiales, cuyo análisis realizado por Franco (2009) y el MOVICE (2013), dan cuenta de su uso como correa de transmisión para la difusión de un discurso estigmatizante y distorsionado hacia la labor de las organizaciones de Derechos Humanos $\mathrm{y}$, en general, hacia el liderazgo social.

Por último, el gobierno de Juan Manuel Santos (2010-2018) se caracterizó por las expectativas de paz y de reparación a las víctimas del conflicto sociopolítico armado. Por un lado, se aprobó la Ley 1448 del 2011 o Ley de Víctimas, cuyo objetivo se orientó a 
establecer un conjunto de medidas judiciales, administrativas, sociales y económicas, individuales y colectivas para las víctimas de las infracciones al Derecho Internacional Humanitario y los Derechos Humanos. Por otro lado, se estableció el Marco Jurídico para la Paz en Julio de 2012, el cual permitió abrir la ventana para el desarrollo de los Diálogos de Paz de La Habana con las FARC-EP, que permitió en un periodo de cuatro años adelantar un proceso de conversaciones que culminó con la firma de dos Acuerdos de Paz, uno en Septiembre y otro en Noviembre del año 2016. Sin embargo, dichas medidas no evitaron que la estrategia contrainsurgente cesara, por el contrario, las cifras de situaciones en contra del liderazgo social en el país fueron creciendo de manera variada con el transcurrir de los años del gobierno Santos, de acuerdo con las cifras de la Tabla 1 del Programa Somos Defensores (2019):

Tabla 1. Cifras de agresiones contra líderes y lideresas sociales-Años 2010-2018

\begin{tabular}{lcccccccccc}
\hline Tipo & $\mathbf{2 0 1 0}$ & $\mathbf{2 0 1 1}$ & $\mathbf{2 0 1 2}$ & $\mathbf{2 0 1 3}$ & $\mathbf{2 0 1 4}$ & $\mathbf{2 0 1 5}$ & $\mathbf{2 0 1 6}$ & $\mathbf{2 0 1 7}$ & $\mathbf{2 0 1 8}$ & Total \\
\hline Amenazas & 109 & 140 & 202 & 209 & 488 & 539 & 317 & 370 & 583 & 2957 \\
Asesinatos & 32 & 49 & 69 & 78 & 55 & 63 & 80 & 106 & 155 & 687 \\
Atentados & 21 & 20 & 50 & 39 & 41 & 35 & 49 & 50 & 34 & 339 \\
Detenciones & 11 & 23 & 26 & 22 & 23 & 26 & 17 & 23 & 4 & 175 \\
Desapariciones & 0 & 6 & 5 & 1 & 1 & 3 & 2 & 0 & 4 & 22 \\
Judicializaciones & 1 & 1 & 1 & 10 & 8 & 8 & 9 & 9 & 19 & 66 \\
Violencia sexual & 0 & 0 & 1 & 0 & 0 & 0 & 1 & 0 & 0 & 2 \\
Robo de & & & & & & & & & & \\
información & 0 & 0 & 3 & 7 & 10 & 8 & 6 & 2 & 6 & 42 \\
\hline \multicolumn{1}{c}{ Total } & $\mathbf{1 7 4}$ & $\mathbf{2 3 9}$ & $\mathbf{3 5 7}$ & $\mathbf{3 6 6}$ & $\mathbf{6 2 6}$ & $\mathbf{6 8 2}$ & $\mathbf{4 8 1}$ & $\mathbf{5 6 0}$ & $\mathbf{8 0 5}$ & $\mathbf{4 2 9 0}$ \\
\hline
\end{tabular}

Fuente: Programa Somos Defensores (2019, p. 95)

De esta forma, es posible afirmar que, en la actualidad, el panorama de la estrategia contrainsurgente presenta una serie de cambios y permanencias en comparación con la década de 1970: la figura del Estado de Sitio no es característica en los últimos veinticinco años, a pesar de que no se encuentra proscrita sino modificada en la Constitución Política de 1991 y ésta ha sido proclamada en pocas ocasiones, la última durante el gobierno de Uribe Vélez. Por otro lado, aún se conocen denuncias por parte de organizaciones de Derechos Humanos sobre la presencia, control territorial y acciones de hostigamiento hacia el liderazgo social por parte de configuraciones paramilitares, en especial en los territorios anteriormente ocupados por las FARC-EP, antes de su finalización como insurgencia armada; al igual que la continuación de las ejecuciones extrajudiciales y acciones encubiertas por parte de la fuerza pública, lo que hace pensar que esta táctica propia de la "guerra sucia" de la década de 1980 aún permanece en el escenario colombiano, al igual que la estrategia de la supuesta "guerra jurídica" de las organizaciones de Derechos Humanos hacia las instituciones castrenses. 
Sumado a ello, no se conoce con seguridad si los Manuales de Contrainsurgencia otorgados en las décadas de 1960 y 1970 por el ejército de Estados Unidos al ejército colombiano continúan siendo material de estudio para la formación de militares. Sin embargo, de acuerdo a una sentencia del Consejo de Estado del año 2009, y compartida por la CCJ (2013), se deduce que aún son utilizados dichos manuales, lo cual es preocupante debido a que en la Doctrina Militar actual mantendrían vigencia conceptos como "enemigo interno", "subversión" y los mecanismos de contrainsurgencia que han sido sumamente criticados por organizaciones de Derechos Humanos de orden nacional e internacional, por el nivel de vulneración al que son sometidas las contrapartes en el conflicto y la población civil.

Sin embargo, las transformaciones evidenciadas en el presente panorama no hubieran sido posibles sin la intervención activa de las organizaciones de Derechos Humanos que, como se logrará evidenciar, han pasado por un proceso permanente de cualificación gracias a las destrezas y habilidades adquiridas en los territorios, lo cual ha permitido la profesionalización de su ejercicio y la inserción de personal formado para la defensa de los Derechos Humanos de la población.

\section{Derechos Humanos y Trabajo Social en Colombia: inserción a un movimiento}

Michael Ignatieff (2001) afirma que, en materia de Derechos Humanos, de 1945 a la fecha ha tenido lugar una triple revolución:

- Legal: la amplia reorganización de un orden normativo puesta en marcha a partir de la Carta de las Naciones Unidas y la Declaración Universal de 1948, y otras normatividades de orden internacional, que condenan las agresiones entre las naciones y el genocidio, establece un mecanismo de protección a los grupos "minoritarios" contra el exterminio, y establece un marco de reglamentación de los conflictos armados.

- Aplicativa: con respecto al tratamiento de los crímenes de guerra, los genocidios y los crímenes de lesa humanidad, y

- Activista: con respecto a la ruptura de los estados en la conducción de los asuntos internacionales, dando voz a la sociedad civil, en especial mediante la figura de las Organizaciones No Gubernamentales, ONG.

Frente a esta triple "revolución", las organizaciones de Derechos Humanos en Colombia surgen en un contexto donde, si bien el estado colombiano reconoce algunos de los Pactos internacionales firmados por la Organización de las Naciones Unidas, dicho reconocimiento tan solo es formal porque se centra en el ejercicio libre ciudadano de 
Castaño-Orozco y Patiño-Martínez

algunos derechos civiles y políticos y desconoce una política oficial de Derechos Humanos (Romero, 2010). Además, es posible afirmar que el movimiento por la defensa de los Derechos Humanos en Colombia ha atravesado por diferentes etapas, en una relación dicotómica entre el compromiso de su labor a favor de los sectores sociales y populares, y su relacionamiento con el Estado colombiano y otras organizaciones de carácter internacional.

Para efectos del presente texto, se utiliza la periodización propuesta por la antropóloga Winifred Tate (2006), quien realiza un estudio pormenorizado del activismo de los Derechos Humanos en el país, en el que identifica dos etapas en la historia de este movimiento. Una primera etapa, compuesta entre las décadas de 1970 y mediados de 1980, tiene que ver con el surgimiento de las primeras organizaciones de Derechos Humanos en el país y, en general, con la apropiación del discurso de los Derechos Humanos, principalmente por parte de las organizaciones sociales y populares de izquierda. En ese periodo surgen organizaciones como el Centro de Investigación y Educación Popular CINEP en 1972, el Comité de Solidaridad con Presos Políticos en 1973, el Colectivo de Abogados José Alvear Restrepo en 1978, el Comité Permanente por la Defensa de los Derechos Humanos en 1979, la Asociación de Familiares de Detenidos y Desaparecidos ASFADDES en 1982, la Comisión Regional de Derechos Humanos del Magdalena Medio CREDHOS en 1987, y la Comisión Colombiana de Juristas en 1988.

Estas organizaciones, de acuerdo con Tate, presentan algunas características en común durante este primer periodo: sus activistas aprenden de Derechos Humanos por cuenta de otros activistas, provenientes principalmente del Cono Sur del continente, quienes se encargan de esparcir sus conocimientos a través de la Educación Popular en un esfuerzo por "despertar conciencias" entre los sectores populares ante la situación de Derechos Humanos, tanto en los países gobernados por las dictaduras militares como en el caso de Colombia. De igual forma, estas organizaciones nacen en el marco de una cultura política protagonizada por dos actores importantes: el Partido comunista y la Iglesia católica, en especial la corriente liberadora protagonizada por personajes como Camilo Torres Restrepo y el grupo Golconda. Por ese motivo, estas organizaciones de Derechos Humanos no dudaban en calificar su ejercicio como de defensa frente a un tipo de violencia existente en el país, como es la violencia perpetrada por el estado colombiano en contra de las organizaciones sociales y populares de izquierda, y de igual forma no ocultaban su admiración y simpatía hacia las organizaciones armadas insurgentes, a las que calificaron como "expresiones legítimas del 'derecho a la rebelión' y la defensa colectiva" (Tate, 2006, p. 73).

De igual manera, las acciones de estas organizaciones en esta primera etapa se concentran en documentar: abusos de autoridad, detenciones arbitrarias y encarcelamiento de activistas, como también asesinatos y masacres cometidas por configuraciones 
paramilitares y militares encubiertas, en un trabajo exclusivamente voluntario de personas que dedican parte de su tiempo al trabajo con los sectores populares en tareas de recolección de información y de concientización, mediante espacios de formación política. Con la documentación debidamente diligenciada y sistematizada, y ante la necesidad de que la situación de Derechos Humanos en el país fuera conocida a nivel internacional, surge la necesidad del relacionamiento de estas organizaciones con otras de carácter internacional, pues al interior del país no contaban con un espacio de interlocución con el gobierno nacional. De acuerdo con Flor Alba Romero (2001):

El espacio público para la labor de las ONG era precario en ese período, ya que no contaban con posibilidades de interlocución con las autoridades, las cuales no aceptan la ocurrencia de atropellos denunciados, eludían su deber de promover y difundir los derechos humanos y además le daban tratamiento de prohibido, peligroso y subversivo al tema, calificando a los defensores como enemigos del Gobierno y apátridas. (p. 447).

Producto de la presión ejercida por las nacientes organizaciones a nivel internacional, la ONG Amnistía Internacional visita el país el 15 de enero de 1980, y como resultado surge un informe donde se reconoce la existencia de presos políticos y se confirman los graves casos de violación a los Derechos Humanos denunciados por dichas organizaciones. A pesar de las duras críticas de este informe al gobierno de Turbay Ayala, éste opta finalmente por derogar el Estatuto de Seguridad. Igualmente, permite la presencia de la Comisión Interamericana de Derechos Humanos $\mathrm{CIDH}$ en los juicios a presos políticos, se concede la liberación de 400 de éstos, se firma una amnistía general a los opositores armados del Estado, y se someten a escrutinio internacional las acciones de sus fuerzas militares, así como la restricción de los instrumentos que el gobierno les había otorgado para el manejo del orden público. Sin embargo, de acuerdo con Bitar (2007) estas concesiones tácticas no representan un compromiso real del gobierno hacia el respeto de los Derechos Humanos, sino una respuesta estratégica frente a la posibilidad de que el país perdiera algún tipo de ayuda económica y militar, como también la posibilidad para el Estado colombiano de contar con apoyo diplomático y mantener una buena imagen ante la comunidad internacional.

Más tarde, el gobierno de Belisario Betancur oficializa la Ley 35 de 1982, mediante la cual son puestas en libertad más de 1.500 personas detenidas con motivo de la aplicación del Estatuto de Seguridad. A partir de ese momento, además de documentar las violaciones a los Derechos Humanos cometidas por el Estado y las configuraciones paramilitares, las organizaciones de Derechos Humanos se enfocan en apoyar los diálogos entre los gobiernos de turno con las insurgencias, la exigencia de un cese al fuego bilateral, y la exigencia de reformas sociales y políticas acordes a las necesidades del momento; el desmonte del paramilitarismo, así como la reconstrucción y fortalecimiento de la rama judicial. Esto en contraste con la arremetida sicarial cometida por paramilitares y 
narcotraficantes en contra de organizaciones políticas como la Unión Patriótica ${ }^{6}$ y el Partido Comunista Colombiano, acciones catalogadas a nivel mundial como un genocidio político sui generis en un régimen político democrático.

Por último, en este periodo, frente al surgimiento de instituciones estatales dedicadas a la preservación y defensa de los Derechos Humanos, el gobierno de Virgilio Barco invita a organizaciones como el CSPP, CPDH y la Asociación de Familiares de Detenidos y Desaparecidos ASFADDES, a la Comisión de Derechos Humanos de la Procuraduría, un año antes del surgimiento de la Consejería Presidencial para los Derechos Humanos. Esta y otras acciones precedentes, en esta década en cuestión de muestran que el reconocimiento de los Derechos Humanos va más allá del reconocimiento del Estado colombiano a las convenciones suscritas con las Naciones Unidas; que también dicho reconocimiento es producto de las luchas de las organizaciones que abogaron por su defensa y efectivo ejercicio, en oposición a las violaciones de estos por parte de los gobiernos de turno, razón por la cual las organizaciones de defensa de los Derechos Humanos exigían al Estado en su conjunto, el cumplimiento de su función constitucional como principal garante de dichos derechos y su responsabilidad institucional frente a las violaciones que, como Estado, comete (Romero, 2010).

Producto de este relacionamiento de las organizaciones defensoras de Derechos Humanos con instituciones estatales y organismos internacionales surge, a partir de la década de 1990 hasta la fecha actual, una segunda etapa en el movimiento de Derechos Humanos en Colombia, caracterizado por una profesionalización de su ejercicio de acuerdo a tres elementos: el marco normativo naciente de Derechos Humanos a raíz de la Constitución Política de 1991; la adquisición de destrezas y herramientas jurídicas por parte de las y los defensores de Derechos Humanos; y la adquisición de recursos provenientes de ONG's internacionales para el ejercicio de la defensa de los Derechos Humanos. Esto permite a algunas de las organizaciones -principalmente las de mayor trayectoria activista y política- lograr la conquista de proyectos y, con ello, la captación de personal profesional que trabaja tiempo completo y percibe un salario por sus labores.

Esta etapa de profesionalización conduce, según Tate (2006), a la construcción de reportes "objetivos" que "despolitizan" el conocimiento sobre los Derechos Humanos, la adhesión a estándares legales y el uso de un tono menos apasionado en el contenido de sus informes, de tal modo que en ellos no se explicite la alianza de dichas organizaciones con programas políticos de izquierda. Estos cambios, de acuerdo con la autora, generaron

6 Hay que recordar que la Unión Patriótica surge en el año 1985, en el marco de los Diálogos de Paz de la Uribe inicialmente como una expresión política de las FARC-EP, pero que luego se expande hacia diferentes sectores del campo popular colombiano. Su primera participación en las elecciones de 1986 deja como resultado el apoyo de 320.000 votantes, la elección de 5 senadores, 9 representantes a la Cámara, 14 diputados departamentales, 351 concejales y el nombramiento de 23 alcaldes municipales. 
serios debates al interior de estas organizaciones acerca de la pérdida de radicalidad en sus posturas y en su ejercicio activista como tal, debido, entre otras cosas, al nivel de relacionamiento alcanzado entre estas organizaciones con el Estado colombiano y las demandas de reformas políticas. Sumado a ello, los debates se tornaron tensos entre algunas organizaciones, quienes terminaron compitiendo por los recursos ofrecidos por los aportantes internacionales lo cual, de acuerdo con algunos analistas citados por la autora, es aprovechado por algunas de las organizaciones financiadoras para despolitizar y cooptar algunas de estas organizaciones, las cuales terminan siendo empujadas a una lógica corporativa propia de la desresponsabilización del Estado frente a las políticas sociales, producto de su transformación neoliberal.

Sin embargo, una transformación positiva durante este periodo tiene que ver con que estas organizaciones defensoras de Derechos Humanos logran ocupar un lugar importante dentro del debate político y la opinión pública, logrando con ello conquistas importantes a favor de las víctimas del conflicto y los sectores sociales y populares. Dos ejemplos dan cuenta de ello: el primero tiene que ver con la trabajadora social y defensora de los Derechos Humanos Gloria Cuartas, quien en 1995 logra ocupar la Alcaldía de Apartadó por la Unión Patriótica, mientras que el otro tiene que ver con el esfuerzo realizado por ASFADDES quien, después de una ardua lucha, logró que el delito de desaparición forzada fuera tipificado como tal en el Código Penal Colombiano a través de la Ley 589 del 2000.

No obstante, cabe destacar que, a partir del presente Siglo XXI, ha surgido un interesante proceso de fortalecimiento conjunto $y$ trabajo coordinado entre las organizaciones de Derechos Humanos a nivel nacional. Muestra de ello es la identificación de tres grandes plataformas de Derechos Humanos como son: el Movimiento Nacional de Víctimas de Crímenes de Estado MOVICE, creado el 25 de Junio del 2005, a raíz de un encuentro nacional al que asistieron más de 10.000 delegados de 230 organizaciones de todo el país. Esta coalición es la alianza más representativa entre asociaciones de familiares de desaparecidos, organizaciones de personas desplazadas, comunidades étnicas perseguidas y sobrevivientes de procesos sociales. La segunda plataforma es la Alianza de Organizaciones Sociales y Afines por una Cooperación Internacional para la Paz y la Democracia en Colombia -más conocida sencillamente como La Alianza-, conformada por 125 organizaciones en el año 2003. Por último, está la Coordinación Colombia-EuropaEstados Unidos CCEEUU, la cual surge en el año 1992 y que, hasta la fecha, recoge alrededor de 281 organizaciones, con las cuales se tiene un trabajo de relacionamiento ante el Consejo de Derechos Humanos de las Naciones Unidas, instituciones europeas, autoridades norteamericanas y colombianas. Dichas plataformas han logrado consolidarse en el debate político como voces representativas de las víctimas de las violaciones a los Derechos Humanos en el marco del conflicto sociopolítico armado, logrando incidir en las discusiones sobre asuntos álgidos en temas de paz y Derechos Humanos, como el debate 
sobre la Ley 975 del 2005 y la supuesta “desmovilización" paramilitar; la construcción, alcance y aplicación de la Ley 1448 de 2011 y la Estrategia Nacional de Derechos Humanos 2014-2034; los Diálogos de Paz entre el gobierno colombiano y la Delegación de Paz de las FARC-EP, en la Habana y su posterior implementación.

A su vez, la profesionalización del movimiento de Derechos Humanos ha permitido que la defensa de estos derechos se convierta en un campo de acción para el ejercicio profesional en el Trabajo Social, bien sea a partir del trabajo asalariado a tiempo completo o bien sea mediante el trabajo voluntario que cada profesional dedica dentro de un compromiso ético-político profesional y -en algunos casos- de militancia política. Sin embargo, a la hora de hacer un análisis acerca de reflexiones académicas producidas en el gremio, lo encontrado sobre el tema es poco, a excepción de trabajos realizados por Bello (2005), Millán (2011), Dueñas y Vélez (2015), así como reflexiones propias publicadas en otros medios (Castaño, 2019a; 2019b). De esta forma, a pesar de los esfuerzos ya iniciados desde diversas orillas profesionales, persiste un déficit reflexivo en cuanto al papel que juega la profesión a la hora de defender los Derechos Humanos de las víctimas del conflicto sociopolítico armado en Colombia y, en general, a la hora de proponer posturas gremiales frente a los fenómenos que atraviesan la realidad colombiana en términos de las desigualdades existentes, producto de la lógica de acumulación capitalista y el cierre del escenario político para dichas víctimas.

\section{Posibilidades de acción desde el Trabajo Social en Derechos Humanos: sobre tiempos de incertidumbre y esperanza}

Por lo anteriormente expuesto, el accionar de las organizaciones de Derechos Humanos en general, y la participación del gremio profesional dentro de la defensa de los Derechos Humanos en Colombia, resulta crucial en un contexto tan complejo y contradictorio como el colombiano. El panorama que se ha expuesto obliga a que actores sociales se involucren en la labor de regular y/o mitigar los impactos que se generan y propender por el respeto y la exigibilidad de los derechos de las víctimas, como producto del accionar guerrerista de los diversos actores armados y políticos quienes, no solamente hostigan mediante el ejercicio de las armas, sino también mediante la estigmatización y la calumnia frente a tan importante ejercicio.

Se reitera la necesidad de que la profesión adquiera un protagonismo fundamental en lo que se refiere a las principales problemáticas que aquejan a nuestro país. Si bien en este momento se ha logrado llegar a unos acuerdos con una de las insurgencias históricas de este país -nos referimos a las Fuerzas Armadas Revolucionaras de Colombia, Ejército del Pueblo FARC-EP-, el proceso de transición ha sido realmente tortuoso, no solamente por la existencia de los demás grupos armados insurgentes y paramilitares, sino también por la desidia del gobierno a la hora de llevar a cabo los acuerdos pactados. Es por eso que 
la labor de las y los trabajadores sociales en contextos de la defensa de los Derechos Humanos en el marco del postacuerdo no pierde vigencia, ni mucho menos, pierde su carácter en el marco del conflicto sociopolítico armado que aún permanece. Así pues, es posible establecer una serie de desafíos en cada uno de los marcos de acción en los que incide la profesión como son: la formación profesional, la investigación social, la praxis profesional, y la organización gremial.

Dentro de la formación profesional es necesario fortalecer los contenidos respecto a la historia reciente de nuestro país, en especial del conflicto sociopolítico armado y su relación con la construcción de sociedad y ciudadanía. En esa medida, es necesario reconocer las diferentes lecturas existentes frente a los detonantes que ocasionaron las guerras en nuestro país, como también la presencia e incidencia de determinados actores que participaron en ella, y los impactos de la misma en el actual contexto, en relación con las dinámicas económicas, políticas y culturales propias del desarrollo del orden social capitalista en Colombia. Resulta necesario fomentar la curiosidad frente a la existencia y permanencia de fenómenos como las insurgencias, el paramilitarismo y las organizaciones defensoras de los Derechos Humanos, a partir de una lectura crítica y problematizadora que permita entender sus lógicas de funcionamiento y establecimiento de relaciones con otros actores, como el Estado y la sociedad civil, en términos del reconocimiento de estas relaciones, sus tensiones y contradicciones, en el marco de la lucha de clases que se desarrolla de forma sui generis en un contexto como el nuestro. En esa medida, la creación de una Cultura de Paz en el escenario colombiano debe incidir en la formación de personas con capacidad de comprensión y análisis crítico del desarrollo del conflicto y la violencia política en sus diferentes dimensiones, y de acuerdo con las particularidades propias de los territorios y los actores presentes en su interior, reconociendo el papel de las organizaciones de Derechos Humanos en este contexto. Así mismo la formación debe evidenciar los motivos por los cuales éstos han sido perseguidos hasta la actualidad por parte del paramilitarismo y el Estado colombiano, en especial las Fuerzas Militares.

De esta forma será posible encauzar esta comprensión y análisis crítico al campo de la investigación social, lo cual determina nuestro segundo campo de desafíos. Se dirá que la historia del conflicto sociopolítico armado colombiano ha sido suficientemente escrita y debatida al interior de los círculos académicos, sin embargo en los territorios quedan muchas historias que se escapan de este ámbito, que transitan por medio de crónicas ocultas y que logran salir a flote gracias a la empiria investigativa de muchas organizaciones sociales que han logrado reconstruir el tejido social a partir de la recuperación de historias que surgen de la tierra excavada y del rio cuyo cuerpo mece en su recorrido ${ }^{7}$. De esta forma, el Trabajo Social, como uno de los campos que aportan a la

7 Iniciativas en ese sentido se encuentra en la Asociación de Familiares de Víctimas de Trujillo AFAVIT y del Sindicato de Trabajadores Agrarios Independientes del Meta SINTRAGRIM en la región del Ariari, quienes 
Castaño-Orozco y Patiño-Martínez

investigación en Ciencias Sociales, cuenta con una oportunidad a la hora de dar a conocer estas crónicas ocultas y llevar a cabo el reconocimiento del papel que han jugado tanto las organizaciones sociales como las y los defensores de Derechos Humanos en sus territorios. Este desafío debe abstraerse de las discusiones al interior de la profesión sobre la necesidad de construir un objeto y método "propio", que permita hacer distinción de las demás ciencias sociales. Por el contrario, en el campo investigativo el Trabajo Social debe apropiarse sin ningún rubor de las diferentes teorías sociales y entablar un diálogo entre ellas y el fenómeno social por tratar, aportando de esta forma a la construcción de un conocimiento científico, despojado de afanes "endogenistas" y "epistemologistas" 8 y más bien dirigido hacia el fortalecimiento, no solo de la comprensión de la realidad social como punta de lanza para su transformación, sino también para el enriquecimiento de las bases que fundamentan la formación, la investigación y el debate profesional, articulado bajo la inseparable llave dialéctica teoría-praxis (Sierra, 2012). En esa medida, Carlos Montaño se manifiesta afirmando que:

La profesión que no invierta en la investigación de la realidad, de los nuevos fenómenos (o el mismo de las nuevas determinaciones de fenómenos ya existentes) estableciendo tendencias sobre el devenir social, desarrollando a partir de ahí nuevas propuestas interventivas y nuevas respuestas, no conseguirá reproducirse en cuanto tal, cuando el contexto social y las demandas cambien. La investigación social, de la realidad socioeconómica y política y de sus fenómenos concretos, no apenas sirve para fundamentar la práctica inmediata, sino fundamentalmente para visualizar las tendencias de la sociedad y las demandas emergentes, pudiendo de esta forma establecer nuevas propuestas interventivas, nuevas respuestas (y por lo tanto, nuevas prácticas y campos profesionales) y tal vez una nueva racionalidad, funcionalidad y legitimación. (Montaño, 1998, p. 184).

Como la realidad social es cambiante dada su complejidad y su carácter contradictorio en sí misma, la investigación social en Trabajo Social debe apostar a captar dichos cambios, interpretarlos y actuar en consecuencia sobre éstos, promoviendo el bienestar colectivo. Es por ello que el tercer desafío se dirige hacia la praxis profesional, entendida esta como movimiento dirigido hacia la acción transformadora de la realidad. Y no es para menos, en un contexto de postacuerdo y de transición sociopolítica, la profesión se halla en un momento de oportunidad para establecer un punto de ruptura en el que puede sacudirse de las demandas "tradicionales" impuestas a nivel histórico de acuerdo a su "base funcional/laboral" (Montaño, 1998). El objetivo de la profesión ha estado históricamente dirigido en Colombia hacia la atención de la niñez y las familias en contextos guiados por la permanencia y reproducción de las estructuras familiares,

de la mano de instituciones como el Grupo de Memoria Histórica -Ahora Centro Nacional de Memoria Histórica- el CINEP y el Comité Intercongregacional Justicia y Paz, lograron publicar informes que dieron cuenta de la magnitud del conflicto en sus territorios.

8

Para una profundización sobre el tema, ver Montaño (1998) y Sierra (2012) 
guiadas bajo una perspectiva sistémica que aísla de su análisis y acción al conflicto social y sus diversas manifestaciones dentro de la cuestión social.

Llegar a ese punto de ruptura supone el reconocimiento de nuestra profesión dentro de la división social del trabajo y ubicar nuestro accionar dentro de las relaciones sociales de clase que soportan las manifestaciones de poder económico, político y culturalideológico (Iamamotto, 2001). De esta forma, una nueva arquitectura estatal en el proceso de transición en el postacuerdo que se construye en nuestro país implicará desde el ejercicio profesional nuevas formas de acción. Sin embargo, dicha acción no podrá estar exenta de una reflexión ética que sacuda el marco de lo moral-valorativo para transcurrir necesariamente hacia el establecimiento de una posición ontológica frente a los fenómenos de la realidad social que nos circunda, para el presente caso el accionar de las organizaciones defensoras de Derechos Humanos, su persecución por parte de diferentes actores sociales y el compromiso del conjunto profesional frente estos hechos.

Por otra parte, dicha reflexión ético-política, debe ubicarse en el marco de los proyectos societarios que en este país -y a nivel global- permanecen en disputa. Es decir, la praxis profesional de las y los trabajadores sociales en el marco del contexto señalado deberá ubicarse, si existe una posición realmente comprometida con las víctimas del conflicto y la satisfacción de sus demandas de verdad, justicia, reparación y exigencias/garantías de sus derechos, a establecer una postura de superación de las relaciones sociales basadas en la acumulación flexible de capital y sus formas de manifestación en detrimento de los Derechos Humanos como las manifestadas anteriormente: persecución a la oposición política, ejercicio de la "guerra sucia" contra el liderazgo social, prevalencia de los derechos del capital sobre los derechos de las comunidades, etc.

Esta propuesta de accionar, si espera devenir en praxis, deberá ser una acción consciente y colectiva. Sin embargo, uno de los inconvenientes para su efectiva concreción tiene que ver con el aislamiento de sus acciones y con la falta de organización gremial de la profesión la cual, aparte de ser incipiente en este país, no cuenta con un peso real ante el gremio y la opinión pública en cuanto al posicionamiento de posturas frente a los fenómenos que afectan la realidad social colombiana. De ahí que el cuarto desafío tiene que ver con la promoción, desarrollo y fortalecimiento del gremio profesional del Trabajo Social que, lejos de confundirse con la militancia político-partidaria, es un elemento fundamental dentro de la profesión por cuanto ésta unifica demandas y aspiraciones del conjunto gremial ante instancias estatales y del sector privado. Por esta razón la organización surge como una instancia que legitima el ejercicio profesional y, a su vez, permite la generación de escenarios de articulación con otras instancias gremiales, centrales trabajadoras, organizaciones y movimientos sociales, en aras de consolidar alianzas que permitan la "articulación entre fuerzas progresistas comprometidas con la 
Castaño-Orozco y Patiño-Martínez

formulación de proyectos societarios que impulsen el desarrollo económico y social de la nación, incorporando los intereses de las mayorías en las grandes decisiones políticas" (Iamamotto, 2003, p. 177).

Estos desafíos tan solo constituyen unos elementos para fomentar una mayor participación del Trabajo Social en su materialidad en el ejercicio de la defensa, promoción y garantías de los derechos de las víctimas del conflicto sociopolítico armado en un escenario histórico donde la construcción de paz en Colombia apenas inicia. Por tanto, los retos que conlleva la existencia de tal escenario señalan la necesidad de pensar nuevos escenarios para el proyecto profesional, que superen los escenarios clásicos promovidos por la Iglesia Católica y el empresariado nacional y logren ajustarse más a las necesidades concretas de una población que, a pesar de los esfuerzos de diferentes actores, resultan insuficientes en lo concerniente a la materialización de una Justicia Social que garantice el bienestar colectivo que conduzca a este país por los senderos de una Paz integral y democrática.

\section{Referencias bibliográficas}

Andreu, F. (2001). Derechos Humanos en Colombia: tres décadas de violaciones e impunidad. En M. Alcántara y J.M. Ibeas (Eds.), Colombia ante los retos del Siglo XXI: desarrollo, democracia y paz. España: Ediciones Universidad de Salamanca.

Arenas, H., y Girón, A. (2014). Gotas que agrietan la roca. Crónicas, entrevistas y diálogos sobre territorios, acceso a la justicia y derechos fundamentales. Bogotá: Siglo del Hombre Editores.

Bello, M.N. (2005). Trabajo Social en contextos de violencia política. Trabajo Social, (7), 9-20.

Bitar, S. (2007). Los primeros pasos de los Derechos Humanos en Colombia: La adaptación estratégica en el gobierno de Julio César Turbay. Bogotá: Ediciones Uniandes.

Calvo-Ospina, H. (2008). Colombia, laboratorio de embrujos. Democracia y Terrorismo de Estado. Madrid: Editorial Foca.

Castaño, C. (2019a). Entre faldas y embrujos: investigar en Trabajo Social para una transición política en Colombia. En W. Mestizo (Comp.), XXII Seminario Latinoamericano y del Caribe de Escuelas de Trabajo Social - Memorias (pp. 182-190). Bogotá: CONETS.

Castaño, C. (2019b). El ejercicio profesional del Trabajo Social con organizaciones de Derechos Humanos: posibilidades, retos y oportunidades. Revista Eleuthera, (21), 168191.

Castaño, C., y Patiño, R. (2016). Constitución de la Red Popular para la Defensa de los Derechos Humanos en el Valle del Cauca 2014-2015. Sistematización de una experiencia (Tesis de pregrado). Universidad del Valle, Escuela de Trabajo Social y Desarrollo Humano. Cali, Colombia. 
Castaño-Orozco y Patiño-Martínez

Centro de Investigación y Educación Popular-CINEP. (2004). Deuda con la humanidad. Paramilitarismo de Estado en Colombia 1988-2003. Bogotá: CINEP.

Centro de Investigación y Educación Popular-CINEP. (2011). Deuda con la humanidad 2: 23 años de Falsos Positivos (1988-2011). Bogotá: CINEP.

Centro Nacional de Memoria Histórica. (2014). "Patrones" y campesinos: tierra, poder y violencia en el Valle del Cauca (1960-2012). Bogotá: CNMH.

Centro Nacional de Memoria Histórica.(2018). Paramilitarismo. Balance de la contribución del CNMH al esclarecimiento histórico. Bogotá: CNMH.

Comisión Colombiana de Juristas-CCJ. (2013). Desafiando la intransigencia. Bogotá: CCJ; $\mathrm{CNMH}$.

Congreso de Colombia. (10 de junio del 2011).Ley de víctimas. [Ley 1448 de 2011]. DO: 48.096.

Congreso de Colombia. (16 de diciembre de 1968). [Ley 48 de 1968]. DO: 32.679.

Congreso de Colombia. (25 de julio del 2005). [Ley 975 de 2005]. DO: 45.980.

Congreso de Colombia. (30 de diciembre de 1993). [Ley 104 de 1993]. DO: 41.158

Congreso de Colombia. (5 de octubre de 1992). [Ley 15 de 1992]. DO: 40.612

Congreso de Colombia. (6 de julio del 2000). [Ley 589 de 2000]. DO: 44.073.

Congreso de Colombia. (19 de noviembre de 1982). [Ley 35 de 1982]. DO: 36.133.

Dueñas, T., y Vélez, G. (2014). Trabajo Social y pedagogía de la memoria desde los Derechos Humanos. Prospectiva. Revista de Trabajo Social e intervención social, (19), 359386.

Estrada, J. (2015). Acumulación capitalista, dominación de clase y rebelión armada. Elementos para una interpretación histórica del conflicto social y armado. En S. De Zubiria et al., Conflicto social y rebelión armada en Colombia: Ensayos críticos (pp. 253318). Bogotá: Editorial Gentes del Común.

Estrada, J. (2008).Capitalismo criminal: Ensayos críticos. Bogotá: Universidad Nacional de Colombia.

Franco, V. (2009). Orden contrainsurgente y dominación. Bogotá: Siglo del Hombre Editores; Instituto Popular de Capacitación.

Giraldo, J. (2015). Aportes sobre el origen del conflicto armado en Colombia, su persistencia y sus impactos. En S. De Zubiria et al., Conflicto social y rebelión armada en Colombia: Ensayos críticos (pp. 205-251). Bogotá: Editorial Gentes del Común.

Grupo de Memoria Histórica. (2013). ¡Basta Ya! Colombia: memorias de guerra y dignidad. Bogotá: CNMH.

Harvey, D. (1998). La condición de la Posmodernidad. Buenos Aires: Amorrortu Editores. Hylton, F. (2006). Evil hour in Colombia. Londres: Verso.

Iamamotto, M. (2001). Servicio Social y división del trabajo. Sao Paulo: Cortez Editora. Iamamotto, M. (2003). Servicio Social en la contemporaneidad. Sao Paulo: Cortez Editora. Ignatieff, M. (2001). Los derechos humanos como política e idolatría. Buenos Aires: Editorial Paidos. 
Castaño-Orozco y Patiño-Martínez

Jiménez, C. (2008). Democracia y neoliberalismo: divergencias y convergencias en la construcción de la Carta Política colombiana de 1991. Medellín: La Carreta Editores.

Millán, D. (2011). Prácticas de memoria afrodescendiente en la reocupación del tiempo y el espacio afectado por el sufrimiento. Trabajo Social, (13), 27-42.

Montaño, C. (1998). La naturaleza del Servicio Social: un ensayo sobre su génesis y reproducción. Sao Paulo: Cortez Editora.

Movimiento de Reconciliación-FOR y Coordinación Colombia-Europa-Estados UnidosCCEEU. (2014). "Falsos positivos" en Colombia y el papel de asistencia militar de Estados Unidos 2000-2010. Bogotá: FOR; CCEEU.

Movimiento Nacional de Víctimas de Crímenes de Estado-MOVICE. (2013).Paz sin crimenes de Estado: Memoria y propuestas de las víctimas. Recuperado de https://www.colectivodeabogados.org/IMG/pdf/libromovice1.pdf.

Orozco-Abad, I. (2005). Sobre los límites de la conciencia humanitaria. Dilemas de la paz y la justicia en América Latina. Bogotá: Editorial Temis.

Palacio, G. (Comp.). (1990). La irrupción del Paraestado: ensayos sobre la crisis colombiana.Bogotá: ILSA-CEREC.

Pax Christi \& Justitia EtPax Netherlands. (1988). Impunity in Colombia. Manuscrito inédito.

Presidencia de la República. (11 de febrero de 1994). [Decreto 356 de 1994]. DO: 41.220.

Presidencia de la República. (14 de abril de 1988). [Decreto 678 de 1988]. DO: 38.293.

Presidencia de la República. (1886). Constitución de la República de Colombia. Bogotá: Imprenta de Vapor de Zalamea Hermanos.

Presidencia de la República. (1991). Constitución Política de Colombia. Bogotá: LEGIS.

Presidencia de la República. (20 de noviembre de 1990). [Decreto 2790 de 1990]. DO: 39.584 .

Presidencia de la República. (24 de diciembre de 1965). [Decreto 3398 de 1965]. DO: 31.842.

Presidencia de la República. (6 de septiembre de 1978). [Decreto 1923de 1978]. DO: 35.101.

Programa Somos Defensores. (2019).La naranja mecánica. Informe Anual 2018. Bogotá: Programa Somos Defensores.

Romero, F. (2001). El movimiento de Derechos Humanos en Colombia. En M. Archila y M. Pardo. (Eds.), Movimientos sociales, estado y democracia en Colombia (pp. 441-472). Bogotá: Universidad Nacional; ICANH.

Romero, F. (2010). La defensa de los Derechos Humanos. Organizaciones y redes en Colombia. En Programa Somos Defensores, Defender y proteger la vida: La acción de los defensores de Derechos Humanos en Colombia (pp. 153-175). Bogotá: Programa somos Defensores.

Ronderos, M. T. (2014).Guerras recicladas. Una historia periodística del paramilitarismo en Colombia. Bogotá: Penguin Random House Grupo Editorial.

Sierra, J.P. (2012).Trabajo Social en Colombia: una propuesta de renovación desde una crítica marxista (Tesis de maestría). Escuela de Servicio Social. Universidad Federal de Rio de Janeiro. Río de Janeiro, Brasil. 
Castaño-Orozco y Patiño-Martínez

Tate, W. (2006). Counting the dead. The culture and politics of Human Rights activism in Colombia. Berkeley: University of California Press.

Terre-Des Hommes, F. (1995).Tras los pasos perdidos de la guerra sucia. Paramilitarismo y operaciones encubiertas en Colombia. Bruselas: Ediciones NCOS.

Vega-Cantor, R. (2015). La dimensión internacional del conflicto social y armado en Colombia. Injerencia de los Estados Unidos, contrainsurgencia y terrorismo de Estado. En S. De Zubiría et al. Conflicto social y rebelión armada en Colombia: Ensayos críticos (pp. 373-443). Bogotá: Editorial Gentes del Común. 


\section{OTROS ARTÍCULOS DE PROSPECTIVA No. 30 DE 2020}

\section{EDITORIAL}

Coherencia, integridad y vida cotidiana

Luz Mary Sánchez-Rengifo

\section{ARTÍCULOS}

Trabajo Social y medios de comunicación: perspectivas y posibilidades de encuentro Social

Mercedes Muriel-Saiz

Maribel Martín-Estalayo

Seguridad, afectos y familias. Obstáculos en el proceso de reintegración de personas desmovilizadas de grupos

armados en Santander, Colombia

Jakeline Vargas-Parra

Ángela María Díaz-Pérez

Priscyll Anctil-Avoine

Reflexividad sobre la intervención profesional en duelo con población afectada por el conflicto armado en Colombia

María Cénide Escobar-Serrano

Maritza Charry-Higuera

Natalia Ramírez-Moncada

Ser mujer indígena, náhuatl, casada, migrante, sin trabajo remunerado: una realidad en los albergues jornaleros agrícolas en Colima, México

Nancy Elizabeth Molina-Rodríguez

Tipos y manifestaciones de la violencia de género: una visibilización a partir de relatos de mujeres víctimas en Soacha, Colombia

Diana Carolina Tibaná-Ríos

Diana Alejandra Arciniegas-Ramírez

Ingrid Julieth Delgado-Hernández

Análisis de necesidades en familias monoparentales con jefatura femenina usuarias de servicios sociales de atención primaria en España

Celia María Fernández-Martínez

Manuela Avilés-Hernández

Experiencias de intervención de trabajadoras sociales con trabajadores sexuales masculinos en Bogotá, Colombia Johan Arturo Barrera-Castellanos
Condiciones laborales de trabajadores sociales en hospitales públicos en la provincia de Mendoza,

Argentina

Cecilia Amalia Molina

Yanina Noemi Roslan-Angeloni

Analía Graciela Correa

Viviana Elena Varela

Gubernamentalidad neoliberal: miradas desde las intervenciones del Trabajo Social en el Gran La Plata, Argentina

Paula Mara Danel

Marcela Claudia Velurtas

Agustina María Favero-Avico

Educación superior en Trabajo Social en Chile y formación para la intervención en situación de calle. Desafios desde la evaluación que interventores hacen de sus procesos de práctica pre-profesional

Carlos Alejandro Andrade-Guzmán

Ignacio Andrés Eissmann-Araya

Educación en Derechos Humanos para el Trabajo Social en Chile: una mirada desde los estándares

internacionales

Lury Soledad Reyes-Pérez

Vivianne Soledad Hasse-Riquelme

Luis Marcelo Silva-Burgos

Arriesgar y preservar la vida: derechos humanos, conflicto sociopolítico armado y Trabajo Social en Colombia

Cristian Sebastián Castaño-Orozco

Ricardo Patiño-Martínez

\section{IN MEMORIAM}

Cristina Bautista Taquinás. Mujer indígena Nasa, Trabajadora Social, lideresa del norte del Cauca, Colombia

Alba Nubia Rodríguez-Pizarro

Lady Johanna Betancourt-Maldonado
ARTISTA INVITADO
MALA JUNTA KLAN
Alejandra Gutiérrez-Cárdenas

\section{PROSPECTIVA}

